\title{
PREFERENCIA ALIMENTAR DE DIONE JUNO JUNO (CRAMER, 1779) (LEPIDOPTERA: NYMPHALIDAE) POR GENÓTIPOS DE MARACUJAZEIRO'
}

\author{
MARINA ROBLES ANGELINI² \& ARLINDO LEAL BOIÇA JÚNIOR ${ }^{3}$
}

RESUMO - O presente trabalho teve por objetivo determinar o efeito de genótipos de maracujazeiro quanto à atratividade e à nãopreferência para alimentação de lagartas de Dione juno juno, em diferentes idades, através de testes com e sem chance de escolha. Os experimentos foram conduzidos no Departamento de Fitossanidade da FCAV/UNESP de Jaboticabal-SP, sob condições ambientais controladas $\left(\mathrm{T}=26= \pm=1{ }^{\circ} \mathrm{C}=\mathrm{U} .=\mathrm{R} .=60 \pm 10 \%\right.$ e fotofase $=14$ horas $)$, utilizando-se dos genótipos Passiflora edulis, $P$. gibertii, $P$. alata, Sul Brasil, IAC-275, Flora FB 300, P. serrato-digitata, P. edulis f.flavicarpa, Maguary FB-100 e P. foetida. Para o teste com chance de escolha, foram utilizadas placas de Petri, onde foram distribuídos, de forma eqüidistante, um disco foliar $(3,2 \mathrm{~cm})$ de cada genótipo estudado e liberando-se em seguida, no centro da placa, 5 lagartas recém-eclodidas ou uma lagarta com 10 dias de idade por material. No teste sem chance de escolha, foi colocado apenas um disco de cada genótipo por placa de Petri ( 9 cm de diâmetro), mantendo-se o mesmo padrão de infestação utilizado no teste com chance. As avaliações foram realizadas em duas etapas, sendo que, na primeira, avaliou-se a atratividade, contando o número de lagartas em cada material a 1;3; 5; 10;15;30;60;120;240 minutos e 24 horas após a liberação das mesmas. Na segunda etapa, observou-se o consumo foliar 24 horas após o início do teste. O genótipo menos atrativo às lagartas recém-eclodidas e de 10 dias de idade foi $P$. alata em testes com e sem chance de escolha. O genótipo $P$. alata foi o menos consumido em teste com chance de escolha, sendo que, no teste sem chance, $P$. alata e $P$. foetida destacaram-se como os menos consumidos para as duas fases larvais.

Termos para indexação: Passiflora spp., resistência de plantas a insetos, lagarta-preta-do- maracujá.

\section{FEEDING PREFERENCE OF DIONE JUNO JUNO (CRAMER, 1779) (LEPIDOPTERA: NYMPHALIDAE) TO PASSION FRUIT GENOTYPES}

\begin{abstract}
This aim of this study was to evaluate the effect of passion fruit genotypes on the attractiveness and feeding nonpreference of $D$. juno juno larvae, through free-choice and no-choice tests. The experiments were carried out at FCAV/UNESP in Jaboticabal-SP, under lab conditions $\left(\mathrm{T}=26 \pm 1{ }^{\circ} \mathrm{C}, \mathrm{RH}=60 \pm 10 \%\right.$ and photophase $=14$ hours $)$, with Passiflora edulis, $P$. gibertii, $P$. alata, Sul Brasil, IAC-275, Flora FB 300, P. serrato-digitata, P. edulis f.flavicarpa, Maguary FB-100 and P. foetida genotypes. In freechoice test, Petri dishes with leaf disks $(3.2 \mathrm{~cm})$ of each genotype were used and distributed at equal distance from the center, and 5 new hatched larvae or one 10-day old larva per genotype were released. In choice test was placed only one leaf disk of each genotype per dish ( $9 \mathrm{~cm}$ in diameter) at the same infestation utilized in free-choice test. Evaluations were carried out in two stages, being first verified the attractiveness, by counting the number of insects on each disk at 1, 3, 5, 10, 15, 30, 60, 120,240 minutes and 24 hours after releasing. In the second stage, leaf consumption was measured 24 hours after beginning the test. $P$. alata was the least attractive genotype to both new-hatched and 10-day old larvae in free-choice and no-choice tests. $P$. alata and $P$. foetida were the least consumed, to both larvae stages.
\end{abstract}

Index Terms: Passiflora spp., host plant resistance, juno silverspot.

\section{INTRODUÇÃO}

Com uma área plantada de aproximadamente 35.000 ha, o Brasil é apontado como o principal produtor mundial de maracujá, tendo como maiores produtores os Estados da Bahia, Sergipe, São Paulo, Pará, Minas Gerais, Ceará, Alagoas e Rio de Janeiro. A área cultivada com maracujazeiros no Nordeste Brasileiro aumentou significativamente nos últimos anos, tornando-se uma das dez espécies frutíferas mais cultivadas no País (Agrianual, 2006).
Mesmo com a expansão das áreas de plantio e produção, a cultura tem sérios problemas fitotécnicos e fitossanitários. Dentre estes, destacam-se os insetos e ácaros, que causam danos consideráveis a essa frutífera, reduzindo sua produtividade (Picanço et al., 1996).

De acordo com Fancelli (1994), entre os insetos-praga do maracujazeiro, destacam-se as moscas-das-frutas, a broca-domaracujazeiro, os pulgões, as vaquinhas, os percevejos, as lagartas desfolhadoras.

A lagarta desfolhadora, Dione juno juno (Cramer, 1779)

\footnotetext{
(Trabalho 169-06) . Recebido em : 30-10-2006. Aceito para publicação em: 27-04-2007.

${ }^{2}$ Doutoranda em Entomologia Agrícola - Departamento de Fitossanidade - Faculdade de Ciências Agrárias e Veterinárias - Câmpus de Jaboticabal/SP. Via de Acesso Prof. Paulo Donato Castellane s/n - 14884 -900. marinaangelini@hotmail.com

${ }^{3}$ Departamento de Fitossanidade (FCAV/UNESP) - Câmpus de Jaboticabal/SP. Via de Acesso Prof. Paulo Donato Castellane s/n - 14884 -900. aboicajr@fcav.unesp.br
} 
(Lepidoptera: Nymphalidae), merece destaque em função dos danos ocasionados e da freqüência de ocorrência. Em infestações severas, o dano torna-se muito intenso, podendo ocorrer desfolha total das plantas de maracujá (Fancelli, 1998).

Boiça Júnior et al. (1999) relataram que a ocorrência de $D$. juno juno é maior na estação de inverno, com pico populacional em julho, seguido da primavera e do verão, cujo pico ocorre em dezembro. Os autores relataram também que os genótipos $P$. alata, $P$. setacea, $P$. coccinea, $P$. nitida, $P$. alata 2 x P. macrocarpa e $P$. edulis x $P$. setacea são pouco infestados por $D$. juno juno, enquanto $P$. cincinnata, $P$. edulis, $P$. edulis $\mathrm{x} P$. alata, $P$. edulis $\mathrm{x}$ $P$. giberti e $P$. caerulea são os mais infestados.

Para o controle desse inseto nas lavouras, o método mais usado pelos agricultores é o químico. Esse procedimento, porém, deixa muito a desejar, pois além de afetar os insetos polinizadores, reduzindo a produção (Santos \& Costa, 1983), acarreta também problemas ambientais e conseqüente desequilíbrio ecológico. Diante disto, outros métodos, como o uso de plantas resistentes, têm sido incentivados (Iara, 1991).

Com relação ao uso de genótipos resistentes em maracujazeiro, há poucos resultados de pesquisas no Brasil, sendo os estudos realizados por Boiça Júnior (1994) e Boiça Júnior et. al. (1999) os pioneiros em relação à resistência de maracujazeiro à D. juno juno.

Em estudos realizados na região de Jaboticabal-SP, sob condições de campo e laboratório, Boiça Júnior (1994) concluiu que os genótipos mais resistentes à $D$. juno juno foram $P$. alata, $P$. setacea, híbrido (P. alata $\times$ X P. macrocarpa), enquanto $P$. edulis f. flavicarpa, híbrido (P. edulis $\mathrm{x} P$. alata) e o híbrido (P. edulis $\mathrm{x}$ $P$. gibertii) foram os mais suscetíveis.

A realização de estudos quanto à possível resistência de diferentes genótipos de maracujazeiro existentes torna-se necessária para que materiais mais adequados possam ser futuramente utilizados no manejo de $D$. juno juno nessa cultura. Neste contexto, o presente trabalho teve como objetivo avaliar, em condições de laboratório, a atratividade e a não-preferência alimentar de lagartas recém-eclodidas e lagartas com 10 dias de idade de $D$. juno juno por genótipos de maracujazeiro através da realização de testes com e sem chance de escolha.

\section{MATERIAL E MÉTODOS}

Os experimentos foram conduzidos no Laboratório de Resistência de Plantas a Insetos, pertencente ao Departamento de Fitossanidade da Faculdade de Ciências Agrárias e Veterinárias (FCAV) - Câmpus de Jaboticabal.

Estudaram-se os genótipos Passiflora edulis, $P$. gibertii, P. alata, Sul Brasil, IAC-275, Flora FB 300, P. serrato-digitata, $P$. edulis f. flavicarpa, Maguary FB-100 e $P$. foetida em relação à atratividade e à não-preferência alimentar de lagartas recémeclodidas e lagartas com 10 dias de idade de Dione juno juno, em testes com e sem chance de escolha. Esses genótipos foram obtidos junto aos Bancos de Germoplasma da FCAV/UNESP e do Instituto Agronômico de Campinas.

Inicialmente, estabeleceu-se uma criação-estoque de $D$. juno juno, sendo que, para isto, posturas provenientes do campo foram coletadas e conduzidas ao laboratório $\left(\mathrm{T}=25 \pm 1^{\circ} \mathrm{C}\right.$, $\mathrm{U}$. $\mathrm{R} .=60 \pm 10 \%$ e fotofase $=14$ horas). Em seguida, estas foram banhadas em hiploclorito de sódio a 1,0\%; posteriormente, foram lavadas em água destilada e acondicionadas sobre papel-filtro umedecido no interior das placas de Petri de $9,5 \mathrm{~cm}$ de diâmetro por 2,0 cm de altura, permanecendo neste local até a eclosão das lagartas. Após isso, as lagartas foram transferidas com auxílio de um pincel macio para ramos de maracujá mantidos no interior de um tubo de PVC (10 cm de altura e diâmetro). Esses tubos foram identificados com a data da eclosão das lagartas, as quais foram posteriormente utilizadas para a instalação dos testes.

Para a instalação dos testes, os genótipos estudados foram divididos em três grupos: Grupo 1 - P. edulis, P. gibertii, $P$. alata, Sul Brasil, IAC-275 e Flora FB 300; Grupo 2 - P. edulis, $P$. alata, P. serrato-digitata, P. edulis f. flavicarpa e Maguary FB100; Grupo 3 - P. edulis, P. alata, Sul Brasil, P. serrato-digitata, $P$. edulis f. flavicarpa, Maguary FB-100 e P. foetida. Em todos os grupos, mantiveram-se como padrões $P$. edulis e $P$. alata, genótipos considerados suscetíveis e resistentes, respectivamente, a D. juno juno (Boiça Júnior et al., 1999). O grupo 3 foi formado a partir dos genótipos mais e menos suscetíveis presentes nos Grupos 1 e 2.

Nos ensaios com chance de escolha, dez discos de cada genótipo (10 repetições) foram confeccionados com auxílio de um vazador de $32 \mathrm{~mm}$ de diâmetro e, após a divisão em grupos, dispostos numa arena composta por uma placa de Petri de vidro (150 mm de diâmetro), forrada com papel-filtro umedecido, para manter a turgidez dos discos foliares. Em cada arena, foram liberadas 5 lagartas recém-eclodidas por genótipo, segundo a metodologia proposta por Boiça Júnior (1994).

A avaliação dos materiais foi feita em duas etapas, sendo que, na primeira, observou-se a atratividade, contando o número de lagartas em cada genótipo a $1 ; 3 ; 5 ; 10 ; 15 ; 30 ; 60,120$ minutos e 24 horas após a liberação. Na segunda etapa, observou-se o consumo foliar, 24 horas após a liberação, ou quando um dos genótipos teve sua área foliar visualmente consumida em 75\%.

Para a verificação do consumo foliar, foram feitas alíquotas semelhantes aos discos oferecidos para as lagartas, sendo essas alíquotas secas em estufa a $40^{\circ} \mathrm{C}$, durante 48 horas, e em seguida pesadas, a fim de obter-se a massa seca das mesmas. Após a última avaliação de atratividade, as lagartas foram retiradas dos discos foliares, sendo estes colocados para secar em estufa a $40^{\circ} \mathrm{C}$ durante 48 horas, a fim de obter-se a massa seca $(\mathrm{mg})$ consumida pelas lagartas.

Os testes com lagartas de 10 dias de idade foram conduzidos de maneira semelhante ao teste com lagartas recémeclodidas; entretanto, nesse caso, liberou-se no interior das arenas apenas uma lagarta com 10 dias de idade por genótipo testado.

No ensaio sem chance de escolha, utilizou-se a mesma metodologia descrita anteriormente, porém colocou-se um disco foliar de cada genótipo por placa de Petri (70 mm de diâmetro), liberando-se no centro da placa 5 lagartas recém-eclodidas de $D$. juno juno ou uma lagarta com 10 dias de idade.

O experimento foi realizado em delineamento inteiramente casualizado, efetuando-se 10 repetições. Os dados obtidos foram 
submetidos à análise de variância, sendo as médias comparadas pelo teste de Tukey, a 5\% de probabilidade.

\section{RESULTADOS E DISCUSSÃO}

Testes com chance de escolha

Analisando-se o teste com lagartas recém-eclodidas (Tabela 1), nota-se que, dentre os genótipos do grupo 1, P. edulis foi o mais atrativo para as lagartas após 10 minutos da liberação, enquanto os demais foram menos procurados pelas lagartas. Não se notou diferença significativa entre os genótipos nos demais tempos de observação; no entanto, $P$. edulis tendeu a apresentar maior atratividade às lagartas. $P$. edulis foi o genótipo mais consumido pelas lagartas, com $720 \mathrm{mg}$ de massa seca consumida, diferindo significativamente de $P$. alata, que apresentou consumo de 707,40 mg. Isto provavelmente ocorreu devido à presença de um maior teor de compostos atraentes nas folhas de $P$. edulis (Tabela 1). Estudos realizados por Lara et al. (1999) quanto à preferência alimentar de D. juno juno, em relação a diferentes genótipos de maracujazeiro, mostraram maior preferência alimentar deste inseto por $P$. edulis ou pelos híbridos contendo essa espécie em relação à $P$. alata. Pela mesma tabela, observa-se uma correspondência entre os resultados obtidos para atratividade e preferência alimentar, onde os genótipos pouco atrativos foram também pouco consumidos.

Em relação aos genótipos do grupo $2, P$. serrato-digitata foi o que atraiu maior número de lagartas 10 minutos após a liberação e a partir de 30 minutos, quando comparado com os demais genótipos estudados. Nota-se, no geral, que os genótipos P. alata, P. edulis f. flavicarpa e Maguary FB-100 foram os menos atrativos para as lagartas. Nesse grupo de genótipos, não foi observada diferença significativa quanto à massa seca de disco foliar consumida pelas lagartas, a qual variou de 707,47 a 709,08 (Tabela 1).

No terceiro grupo, não houve diferença significativa quanto à atração das lagartas para os genótipos nos diferentes tempos de observação. No entanto, pôde-se observar que $P$. alata tendeu a ser menos atrativo para as lagartas, sugerindo a presença de compostos repelentes. Esses resultados corroboram aqueles encontrados por Boiça Júnior (1994), que indicavam $P$. alata como o genótipo menos infestado e menos consumido por D. juno juno em teste com chance de escolha em campo e laboratório, respectivamente, evidenciando a resistência desse material a essa praga. Nesse grupo, também não foram detectadas diferenças entre os genótipos com relação à massa seca de disco foliar consumida pelas lagartas, a qual variou de 707,72 a 712,20 mg (Tabela 1).

Com relação ao teste com lagartas de 10 dias de idade, no grupo 1, o genótipo $P$. gibertii destacou-se como o mais atrativo 2 horas após a liberação (1,33 lagarta), quando comparado aos genótipos Sul Brasil e P. edulis, que atraíram 0,76 e 0,81 lagarta, respectivamente. Quatro horas após o início do teste, o genótipo $P$. gibertii continuou sendo o mais atrativo (1,59 lagarta), diferindo significativamente dos demais. Não se observou diferença significativa entre os genótipos nos demais tempos de observação. Quanto à massa seca de discos foliares consumida pelas lagartas com 10 dias de idade, também não foram detectadas diferenças significativas entre os genótipos (Tabela 2). Neste caso, não houve correspondência entre os resultados obtidos para atratividade e consumo, ou seja, os genótipos mais atrativos, 2 e 4 horas após a liberação das lagartas, não foram os mais consumidos por D. juno juno (Tabela 2).

No grupo 2, todos os genótipos foram igualmente atrativos e consumidos por D. juno juno, não sendo detectadas diferenças significativas durante as observações (Tabela 2).

Entre os genótipos do grupo 3 (Tabela 2), nota-se que, após 5 minutos da liberação dos insetos, o genótipo $P$. serratodigitata foi o mais atrativo (1,17 lagarta), seguido dos genótipos P. edulis, Sul Brasil e Maguary FB-100, que atraíram 0,71 lagarta. Neste grupo, observou-se também diferença significativa após 4 horas da liberação, sendo que o genótipo Maguary FB-100 se destacou com maior número de indivíduos (1,13 lagarta), diferindo de $P$. alata e $P$. foetida, que foram os menos atrativos (ambos com 0,71 lagarta). Quanto à massa seca de discos foliares consumida, não ocorreram diferenças significativas entre os genótipos.

Bianchi \& Moreira (2005), ao estudarem dez espécies de passifloráceas no Rio Grande do Sul, em relação à preferência alimentar de $D$. juno juno, constataram que $P$. edulis foi o genótipo preferido por lagartas recém-eclodidas e de quinto instar desta praga quando comparado a $P$. elegans que foi menos consumido. Esses autores concluíram ainda que as lagartas de D. juno juno têm poucas restrições quanto à preferência alimentar, pois, nos experimentos, não rejeitaram $P$. misera, $P$. tenuifila e $P$. caerulea, indicando que podem alimentar-se de outras passifloráceas quando $P$. edulis está ausente.

\section{Testes sem chance de escolha}

No teste com lagartas recém-eclodidas no grupo 1, o genótipo mais atrativo a 3 minutos após a liberação foi $P$. gibertii, com 1,32 lagarta, diferindo do genótipo Sul Brasil, que atraiu em média 0,85 lagarta (Tabela 3). Após 4 horas, P. gibertii e Sul Brasil foram os mais atrativos, com 2,10 e 2,16 lagartas, respectivamente, diferindo de $P$. alata (1,37 lagarta). Vinte e quatro horas após a liberação das lagartas, o genótipo $P$. alata diferiu dos demais, sendo o menos atrativo (0,87 lagartas), sugerindo a presença de algum fator de resistência. Não se observou diferença entre os genótipos nas demais avaliações (Tabela 3).

No grupo 2, as lagartas levaram 5 minutos para chegar até os genótipos, não sendo observados indivíduos nas duas primeiras observações. Nas observações de 4 e 24 horas após a liberação das lagartas, o genótipo menos atrativo foi $P$. alata, com 1,13 e 0,76 lagarta, respectivamente, diferindo significativamente dos demais. Nas outras avaliações, não foram detectadas diferenças significativas entre os materiais. Em todos os tratamentos, os discos foliares foram igualmente consumidos, indicando a ausência de resistência do tipo não-preferência para alimentação (Tabela 3 ).

Considerando-se os genótipos do grupo 3, observa-se que houve diferença quanto à atratividade das lagartas após 1 minuto da liberação, onde o genótipo menos atrativo foi $P$. edulis 
f. flavicarpa, com 1,63 lagarta, diferindo dos demais, que se mostraram igualmente atrativos por lagartas recém-eclodidas de $D$. juno juno. Após 3 minutos do início do teste, os genótipos $P$. alata e Sul Brasil foram os que atraíram mais insetos, com 1,85 e 1,84 lagarta, repectivamente, diferindo dos genótipos $P$. serratodigitata, Maguary FB-100 e P. foetida, com 1,66; 1,66 e 1,65 lagarta, respectivamente (Tabela 3 ).

O genótipo Sul Brasil atraiu maior número de lagartas 5 minutos após a liberação (Tabela 3), diferindo de P. serratodigitata e Maguary FB-100, que atraíram menos lagartas neste tempo de observação (0,86 lagarta). Sul Brasil foi também o genótipo que apresentou maior número de lagartas 10 minutos após o início das observações, diferindo neste caso de $P$. foetida (0,81 lagarta).

Nas observações de 4 e 24 horas após a liberação (Tabela 3), o genótipo $P$. alata foi o menos atrativo (1,53 e 1,16, respectivamente) para as lagartas recém-eclodidas de $D$. juno juno, enquanto os genótipos mais procurados pelos insetos foram P. edulis (2,23) e Maguary FB-100 (2,32). Boiça Júnior et al. (1999) verificaram que $P$. alata apresenta resistência do tipo nãopreferência para alimentação em relação a $D$. juno juno, possivelmente associada à presença de compostos químicos, capazes de agir como repelentes ou supressores de alimentação. Quanto à massa seca de discos de folhas consumida, houve diferença significativa entre os genótipos, sendo que Sul Brasil foi o genótipo mais consumido pelas lagartas; em contrapartida, $P$. foetida revelou-se o menos consumido $(707,18 \mathrm{mg})$.

Segundo Echeverri et al. (1991), o fato de $P$. foetida não ser atrativa a $D$. juno juno pode ser devido à presença de flavonóides, como o ermanin, que confere a este genótipo uma defesa química, atuando como deterrente de alimentação para esta praga. Esses mesmos autores relataram que o efeito deterrente não é o único presente neste genótipo, pois, quando as lagartas foram alimentadas com folhas impregnadas com o ermanin, houve inibição do crescimento das larvas, indicando uma possível distorção no sistema hormonal das mesmas.

Nos testes com lagartas de 10 dias de idade, não houve diferença significativa entre os genótipos do grupo 1 quanto à atratividade e o consumo foliar, sugerindo uma preferência semelhante do inseto por todos os materiais (Tabela 4). Entre os genótipos do grupo 2, $P$. edulis aparece como o mais atrativo a 1 e 5 minutos após a liberação, com 0,91 e 1,07 lagartas atraídas, respectivamente. Na observação feita a 10 minutos, o $P$. edulis apresentou maior número de lagartas $(1,07)$, diferindo de $P$. alata que foi o menos atrativo $(0,71)$. Nos demais tempos de observações e, em relação ao consumo, não constatou-se diferença entre os genótipos testados.

Nos genótipos do grupo 3 observa-se diferenças significativas a 30 minutos, 4 e 24 horas após a liberação das lagartas, sendo que $P$. edulis mostrou-se menos atrativo em relação a $P$. serrato-digitata 30 minutos após o início do teste; $P$. alata atraiu menor número de lagartas em relação a $P$. serratodigitata e $P$. edulis f. flavicarpa após 4 horas. Na avaliaçãofeita após 24 horas a liberação das lagartas, P. foetida e Maguary FB100 destacaram-se com o maior $(1,02)$ e o menor $(0,71)$ número de lagartas atraídas, respectivamente. A massa seca de discos de folhas consumida pelas lagartas foi semelhante entre os genótipos, variando de 700,49 a 710,00 mg (Tabela 4). Neste caso também não notou-se correspondência entre os resultados obtidos para atratividade e preferência alimentar, onde os genótipos mais atrativos não foram os mais consumidos.

TABELA 1 - Número médio de lagartas recém-eclodidas de Dione juno juno, contadas em diferentes períodos de observação e massa seca consumida de discos foliares de genótipos de maracujazeiro, em teste com chance de escolha. Jaboticabal-SP, 2005.

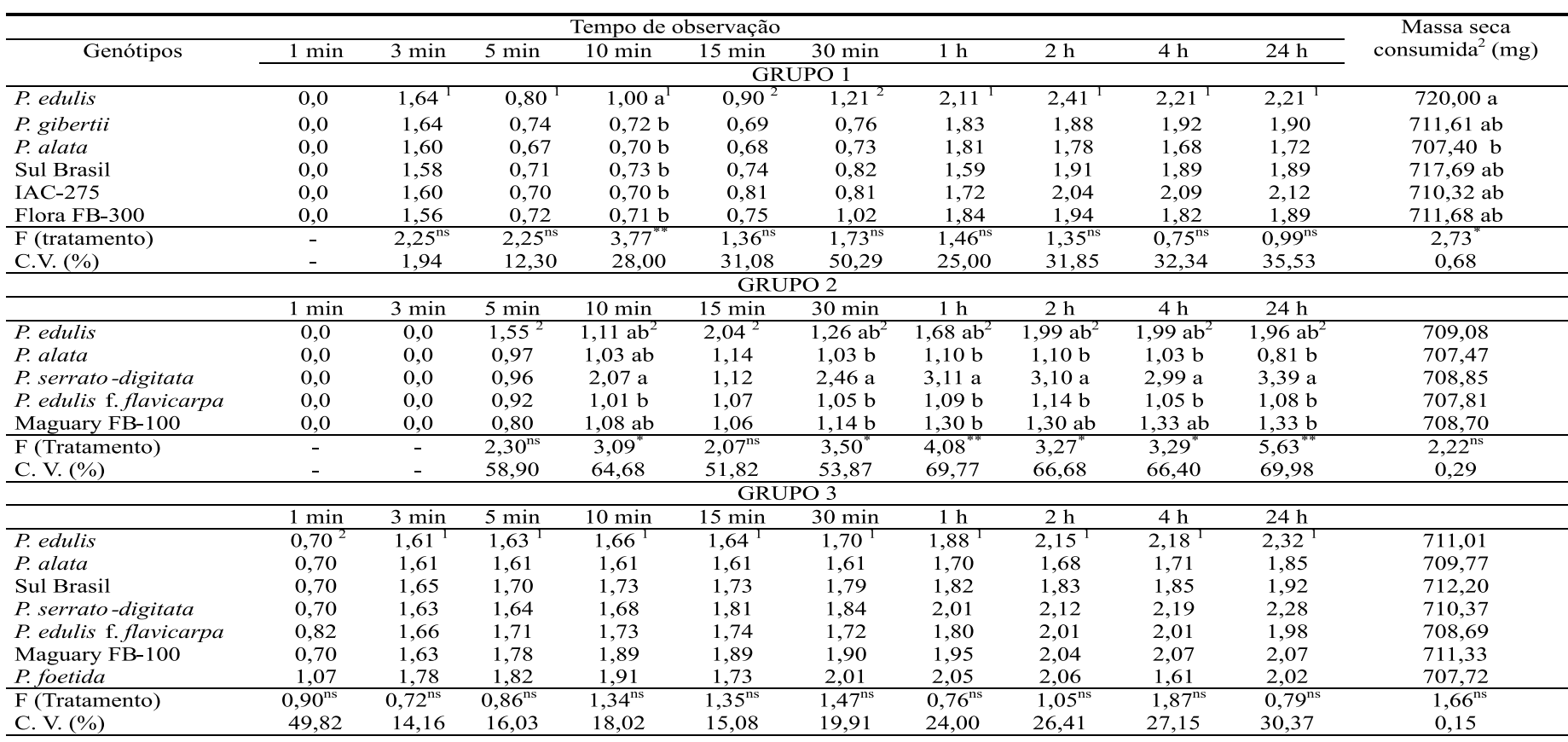

${ }^{1}$ Médias transformadas em $\ln (\mathrm{x}+5,0)$.

${ }^{2}$ Médias transformadas em $(\mathrm{x}+0,5)^{1 / 2}$.

Médias seguidas de mesma letra dentro de cada grupo, na coluna, não diferem significativamente, pelo teste de Tukey, a $5 \%$ de probabilidade. 
TABELA 2 - Número médio de lagartas com 10 dias de idade de Dione juno juno, contadas em diferentes períodos de observação e massa seca consumida de discos foliares de genótipos de maracujazeiro, em teste com chance de escolha. JaboticabalSP, 2005.

\begin{tabular}{|c|c|c|c|c|c|c|c|c|c|c|c|}
\hline \multicolumn{11}{|c|}{ Tempo de observação } & \multirow{3}{*}{$\begin{array}{l}\text { Massa seca consumida } \\
\qquad(\mathrm{mg})\end{array}$} \\
\hline Genótipos & $1 \mathrm{~min}$ & $3 \mathrm{mi}$. & $5 \mathrm{~min}$ & $10 \mathrm{~min}$ & $15 \mathrm{~min}$ & $30 \mathrm{~min}$ & $1 \mathrm{~h}$ & $2 \mathrm{~h}$ & $4 \mathrm{~h}$ & $24 \mathrm{~h}$ & \\
\hline & \multicolumn{10}{|c|}{ GRUPO $1^{1}$} & \\
\hline P. edulis & 0,86 & 0,86 & 0,93 & 0,90 & 0,90 & 0,76 & 0,85 & $0,81 \mathrm{~b}$ & $0,81 \mathrm{~b}$ & 0,91 & 709,89 \\
\hline P. gibertii & 0,76 & 0,79 & 0,79 & 0,80 & 0,80 & 1,05 & 1,25 & $1,33 \mathrm{a}$ & $1,59 \mathrm{a}$ & 1,05 & 708,50 \\
\hline P. alata & 0,70 & 0,71 & 0,91 & 0,90 & 0,91 & 0,81 & 0,88 & $1,03 \mathrm{ab}$ & $1,01 \mathrm{~b}$ & 1,06 & 710,11 \\
\hline Sul Brasil & 0,81 & 0,76 & 0,81 & 0,79 & 0,80 & 0,79 & 0,85 & $0,76 \mathrm{~b}$ & $0,85 \mathrm{~b}$ & 0,81 & 712,87 \\
\hline IAC-275 & 0,76 & 0,79 & 0,84 & 0,83 & 0,82 & 0,88 & 0,88 & $0,82 \mathrm{ab}$ & $0,85 \mathrm{~b}$ & 0,79 & 710,09 \\
\hline Flora FB-300 & 0,85 & 0,85 & 1,04 & 1,00 & 1,02 & 0,93 & 0,76 & $0,86 \mathrm{ab}$ & $0,76 \mathrm{~b}$ & 0,89 & 712,30 \\
\hline F (tratamento) & $0,77^{\mathrm{ns}}$ & $0,59^{\mathrm{ns}}$ & $0,67^{\text {ns }}$ & $1,41^{\text {ns }}$ & $2,27^{\text {ns }}$ & $0,92^{\text {ns }}$ & $1,77^{\mathrm{ns}}$ & $3,13^{* *}$ & $6,47^{* *}$ & $1,00^{\text {ns }}$ & $0,51^{\mathrm{ns}}$ \\
\hline C.V. $(\%)$ & 27,11 & 29,53 & 40,15 & 31,29 & 36,09 & 40,55 & 45,05 & 40,89 & 39,81 & 39,47 & 1,99 \\
\hline \multicolumn{12}{|c|}{ GRUPO $2^{1}$} \\
\hline & $1 \mathrm{~min}$ & $3 \min$ & $5 \mathrm{~min}$ & $10 \mathrm{~min}$ & $15 \mathrm{~min}$ & $30 \mathrm{~min}$ & $1 \mathrm{~h}$ & $2 \mathrm{~h}$ & $4 \mathrm{~h}$ & $24 \mathrm{~h}$ & \\
\hline P. edulis & 0,76 & 0,81 & 0,85 & 0,91 & 0,94 & 1,04 & 0,85 & 0,90 & 1,12 & 0,79 & 708,80 \\
\hline$P$. alata & 0,71 & 0,76 & 0,76 & 0,76 & 0,84 & 0,85 & 0,79 & 0,71 & 1,13 & 0,82 & 708,11 \\
\hline P. serrato-digitata & 0,71 & 0,76 & 0,76 & 0,76 & 0,76 & 0,91 & 0,81 & 0,90 & 1,12 & 0,96 & 707,82 \\
\hline P. edulis f. flavicarpa & 0,71 & 0,76 & 0,85 & 0,81 & 0,81 & 0,86 & 0,87 & 1,12 & 0,91 & 0,82 & 710,63 \\
\hline Maguary FB-100 & 0,76 & 0,76 & 0,80 & 0,90 & 0,86 & 0,81 & 0,81 & 0,85 & 1,13 & 0,76 & 709,71 \\
\hline F (Tratamento) & $0,75^{\mathrm{ns}}$ & $0,17^{\mathrm{ns}}$ & $0,30^{\mathrm{ns}}$ & $0,69^{\text {ns }}$ & $0,47^{\text {ns }}$ & $0,81^{\mathrm{ns}}$ & $0,13^{\mathrm{ns}}$ & $1,47^{\mathrm{ns}}$ & $0,36^{\mathrm{ns}}$ & $0,53^{\mathrm{ns}}$ & $1,90^{\mathrm{ns}}$ \\
\hline C. V. $(\%)$ & 14,22 & 22,88 & 31,40 & 33,94 & 36,38 & 35,66 & 34,76 & 43,97 & 46,32 & 40,43 & 0,37 \\
\hline \multicolumn{12}{|c|}{ GRUPO $3^{1}$} \\
\hline & $1 \mathrm{~min}$ & $3 \mathrm{~min}$ & $5 \mathrm{~min}$ & $10 \mathrm{~min}$ & $15 \mathrm{~min}$ & $30 \mathrm{~min}$ & $1 \mathrm{~h}$ & $2 \mathrm{~h}$ & $4 \mathrm{~h}$ & $24 \mathrm{~h}$ & \\
\hline P. edulis & 0,0 & 0,0 & $0,71 \mathrm{~b}$ & 0,71 & 0,76 & 0,76 & 0,81 & 0,86 & $0,81 \mathrm{ab}$ & 1,00 & 708,80 \\
\hline P. alata & 0,0 & 0,0 & $0,90 \mathrm{ab}$ & 0,94 & 0,95 & 0,93 & 0,85 & 0,87 & $0,71 \mathrm{~b}$ & 0,95 & 708,09 \\
\hline Sul Brasil & 0,0 & 0,0 & $0,71 \mathrm{~b}$ & 0,71 & 0,76 & 0,76 & 0,81 & 0,76 & $0,79 \mathrm{ab}$ & 0,71 & 708,20 \\
\hline P. serrato-digitata & 0,0 & 0,0 & $1,17 \mathrm{a}$ & 1,15 & 1,01 & 1,07 & 1,07 & 0,85 & $0,85 \mathrm{ab}$ & 0,87 & 708,49 \\
\hline P. edulis f. flavicarpa & 0,0 & 0,0 & $0,97 \mathrm{ab}$ & 0,92 & 0,90 & 0,99 & 0,76 & 0,82 & $0,79 \mathrm{ab}$ & 0,81 & 708,19 \\
\hline Maguary FB-100 & 0,0 & 0,0 & $0,71 \mathrm{~b}$ & 0,85 & 0,90 & 0,85 & 1,09 & 1,18 & $1,13 \mathrm{a}$ & 1,15 & 709,03 \\
\hline P. foetida & 0,0 & 0,0 & $0,76 \mathrm{ab}$ & 0,76 & 0,71 & 0,71 & 0,71 & 0,71 & $0,71 \mathrm{~b}$ & 0,88 & 708,30 \\
\hline F (Tratamento) & - & - & $3,24^{* *}$ & $1,64^{\mathrm{ns}}$ & $1,19^{\text {ns }}$ & $1,38^{\mathrm{ns}}$ & $1,99^{\mathrm{ns}}$ & $1,57^{\mathrm{na}}$ & $2,28^{*}$ & $1,31^{\mathrm{ns}}$ & $0,92^{\text {ns }}$ \\
\hline C. V. $(\%)$ & - & - & 36,73 & 45,28 & 38,84 & 42,23 & 39,15 & 44,42 & 36,60 & 43,21 & 0,14 \\
\hline
\end{tabular}

1- Médias transformadas em $(\mathrm{x}+0,5)^{1 / 2}$.

Médias seguidas de mesma letra dentro de cada grupo, na coluna, não diferem significativamente, pelo teste de Tukey, a 5\% de probabilidade.

TABELA 3 - Número médio de lagartas recém-eclodidas de Dione juno juno, contadasem diferentes períodos de observação e massa seca consumida de discos foliares de genótipos de maracujazeiro, em teste sem chance de escolha. Jaboticabal-SP, 2005 .

\begin{tabular}{|c|c|c|c|c|c|c|c|c|c|c|c|}
\hline \multicolumn{11}{|c|}{ Tempo de observação } & \multirow{3}{*}{$\begin{array}{c}\text { Massa seca consumida } \\
(\mathrm{mg})\end{array}$} \\
\hline \multirow[b]{2}{*}{ Genótipos } & \multicolumn{10}{|c|}{ GRUPO 1} & \\
\hline & $1 \mathrm{~min}$ & $3 \mathrm{~min}$ & $5 \mathrm{~min}$ & $10 \mathrm{~min}$ & $15 \mathrm{~min}$ & $30 \mathrm{~min}$ & $1 \mathrm{~h}$ & $2 \mathrm{~h}$ & $4 \mathrm{~h}$ & $24 \mathrm{~h}$ & \\
\hline P. edulis & 0,86 & $1,00 \mathrm{ab} 1$ & $1,07^{2}$ & $1,26^{2}$ & $1,19^{2}$ & $1,24^{2}$ & $1,43^{2}$ & $1,60^{2}$ & $1,71 \mathrm{ab}^{2}$ & $2,14 \mathrm{a}^{2}$ & 711,67 \\
\hline P. gibertii & 1,06 & $1,32 \mathrm{a}$ & 1,30 & 1,24 & 1,51 & 1,48 & 1,67 & 1,87 & $2,10 \mathrm{a}$ & $2,08 \mathrm{a}$ & 716,02 \\
\hline P. alata & 0,93 & $0,89 \mathrm{ab}$ & 0,96 & 1,12 & 1,18 & 1,22 & 1,39 & 1,45 & $1,37 \mathrm{~b}$ & $0,87 \mathrm{~b}$ & 721,30 \\
\hline Sul Brasil & 0,70 & $0,85 \mathrm{~b}$ & 1,06 & 1,05 & 1,25 & 1,30 & 1,41 & 1,88 & $2,16 \mathrm{a}$ & $2,11 \mathrm{a}$ & 711,90 \\
\hline IAC-275 & 0,93 & $1,12 \mathrm{ab}$ & 1,15 & 1,15 & 1,44 & 1,44 & 1,45 & 1,44 & $1,88 \mathrm{ab}$ & $2,10 \mathrm{a}$ & 715,58 \\
\hline Flora FB-300 & 0,93 & $0,93 \mathrm{ab}$ & 1,07 & 1,09 & 1,20 & 1,24 & 1,17 & 1,36 & $1,79 \mathrm{ab}$ & $1,92 \mathrm{a}$ & 717,00 \\
\hline F (tratamento) & $1,33^{\mathrm{ns}}$ & $2,42^{*}$ & $0,60^{\text {ns }}$ & $0,31^{\text {ns }}$ & $0,72^{\mathrm{ns}}$ & $0,50^{\mathrm{ns}}$ & $0,93^{\text {ns }}$ & $1,80^{\text {ns }}$ & $4,58^{* *}$ & $18,59^{* *}$ & $1,39^{\mathrm{ns}}$ \\
\hline \multirow[t]{3}{*}{ C.V. $(\%)$} & 35,87 & 35,03 & 41,28 & 42,07 & 41,09 & 38,49 & 36,87 & 33,26 & 23,15 & 19,39 & 0,50 \\
\hline & \multicolumn{10}{|c|}{ GRUPO 2} & \\
\hline & $1 \mathrm{~min}$ & $3 \mathrm{~min}$ & $5 \mathrm{~min}$ & $10 \mathrm{~min}$ & $15 \mathrm{~min}$ & $30 \mathrm{~min}$ & $1 \mathrm{~h}$ & $2 \mathrm{~h}$ & $4 \mathrm{~h}$ & $24 \mathrm{~h}$ & \\
\hline P. edulis & 0,0 & 0,0 & $0,91^{2}$ & $1,09^{2}$ & $1,18^{2}$ & $1,33^{2}$ & $1,28^{2}$ & $1,45^{2}$ & $1,90 \mathrm{a}^{2}$ & $1,95 \mathrm{a}^{2}$ & 708,09 \\
\hline P. alata & 0,0 & 0,0 & 0,90 & 1,16 & 1,07 & 1,30 & 1,35 & 1,35 & $1,13 \mathrm{~b}$ & $0,76 \mathrm{~b}$ & 708,80 \\
\hline P. serrato-digitata & 0,0 & 0,0 & 0,93 & 1,13 & 1,41 & 1,39 & 1,76 & 1,93 & 2,03 a & $2,06 \mathrm{a}$ & 708,57 \\
\hline P. edulis f. flavicarpa & 0,0 & 0,0 & 1,00 & 1,42 & 1,39 & 1,40 & 1,79 & 1,93 & $2,16 \mathrm{a}$ & $2,14 \mathrm{a}$ & 709,02 \\
\hline Maguary FB-100 & 0,0 & 0,0 & 0,93 & 1,27 & 1,29 & 1,34 & 1,46 & 1,55 & $2,08 \mathrm{a}$ & $2,05 \mathrm{a}$ & 708,19 \\
\hline F (Tratamento) & - & - & $0,09^{\mathrm{ns}}$ & $0,58^{\text {ns }}$ & $0,65^{\text {ns }}$ & $0,05^{\text {ns }}$ & $1,16^{\mathrm{ns}}$ & $1,80^{\mathrm{ns}}$ & $6,75^{* *}$ & $19,70^{* *}$ & $0,37^{\mathrm{ns}}$ \\
\hline \multirow[t]{3}{*}{ C. V. $(\%)$} & - & - & 45,68 & 41,35 & 44,18 & 44,12 & 45,13 & 38,68 & 27,46 & 23,11 & 0,28 \\
\hline & \multicolumn{10}{|c|}{ GRUPO 3} & \\
\hline & $1 \mathrm{~min}$ & $3 \mathrm{~min}$ & $5 \mathrm{~min}$ & $10 \mathrm{~min}$ & $15 \mathrm{~min}$ & $30 \mathrm{~min}$ & $1 \mathrm{~h}$ & $2 \mathrm{~h}$ & $4 \mathrm{~h}$ & $24 \mathrm{~h}$ & \\
\hline P. edulis & $1,75 \mathrm{a}^{1}$ & $1,77 \mathrm{ab}^{1}$ & $1,25 \mathrm{ab}^{2}$ & $1,04 \mathrm{ab}^{2}$ & $1,09^{2}$ & $1,56^{2}$ & $1,78^{2}$ & $2,07^{2}$ & $2,23 \mathrm{a}^{2}$ & $2,30 \mathrm{a}^{2}$ & $708,51 \mathrm{bc}$ \\
\hline P. alata & $1,79 \mathrm{a}$ & $1,85 \mathrm{a}$ & $1,26 \mathrm{ab}$ & $1,38 \mathrm{ab}$ & 1,35 & 1,56 & 1,65 & 1,74 & $1,53 \mathrm{~b}$ & $1,16 \mathrm{~b}$ & $708,11 \mathrm{bc}$ \\
\hline Sul Brasil & $1,77 \mathrm{a}$ & $1,84 \mathrm{a}$ & $1,41 \mathrm{a}$ & $1,52 \mathrm{a}$ & 1,50 & 1,89 & 1,73 & 1,86 & $2,15 \mathrm{ab}$ & $2,32 \mathrm{a}$ & $711,70 \mathrm{a}$ \\
\hline P. serrato-digitata & $1,65 \mathrm{ab}$ & $1,66 \mathrm{~b}$ & $0,86 \mathrm{~b}$ & $1,10 \mathrm{ab}$ & 1,24 & 1,57 & 1,58 & 1,71 & $1,94 \mathrm{ab}$ & $1,80 \mathrm{a}$ & $709,31 \mathrm{abc}$ \\
\hline P. edulis f. flavicarpa & $1,63 \mathrm{~b}$ & $1,68 \mathrm{ab}$ & $0,93 \mathrm{ab}$ & $1,48 \mathrm{ab}$ & 1,35 & 1,06 & 1,24 & 1,90 & $2,10 \mathrm{ab}$ & $2,26 \mathrm{a}$ & $710,20 \mathrm{ab}$ \\
\hline Maguary FB-100 & $1,65 \mathrm{ab}$ & $1,66 \mathrm{~b}$ & $0,86 \mathrm{~b}$ & $1,05 \mathrm{ab}$ & 1,27 & 1,44 & 1,59 & 2,05 & $2,32 \mathrm{a}$ & $2,30 \mathrm{a}$ & $709,20 \mathrm{abc}$ \\
\hline P. foetida & $1,65 \mathrm{ab}$ & $1,65 \mathrm{~b}$ & $0,91 \mathrm{ab}$ & $0,81 \mathrm{~b}$ & 0,86 & 1,27 & 1,23 & 1,73 & $1,84 \mathrm{ab}$ & $2,01 \mathrm{a}$ & $707,18 \quad \mathrm{c}$ \\
\hline F (Tratamento) & $2,29^{*}$ & $2,96^{*}$ & $3,06^{*}$ & $3,06^{*}$ & $1,42^{\text {ns }}$ & $1,82^{\mathrm{ns}}$ & $1,23^{\text {ns }}$ & $0,78^{\text {ns }}$ & $3,30^{* *}$ & $11,31^{* *}$ & $5,54^{* *}$ \\
\hline C.V. $(\%)$ & 8,95 & 9,26 & 38,57 & 39,35 & 44,32 & 41,16 & 40,86 & 28,61 & 23,45 & 19,82 & 0,27 \\
\hline
\end{tabular}

${ }^{1}$ Média transformada em $\ln (\mathrm{x}+5,0)$.

${ }^{2}$ Médias transformadas em $(x+0,5)^{1 / 2}$.

Médias seguidas de mesma letra dentro de cada grupo, na coluna, não diferem significativamente, pelo teste de Tukey, a $5 \%$ de probabilidade 
TABELA 4 - Número médio de lagartas com 10 dias de idade de Dione juno juno, contadas em diferentes períodos de observação e massa seca consumida de discos foliares de genótipos de maracujazeiro, em teste sem chance de escolha. JaboticabalSP, 2005

\begin{tabular}{|c|c|c|c|c|c|c|c|c|c|c|c|}
\hline \multicolumn{11}{|c|}{ Tempo de observação } & \multirow{3}{*}{$\begin{array}{c}\text { Massa seca consumida } \\
(\mathrm{mg})\end{array}$} \\
\hline \multirow[t]{2}{*}{ Genótipos } & $1 \mathrm{~min}$ & $3 \mathrm{~min}$ & $5 \mathrm{~min}$ & $10 \mathrm{~min}$ & $15 \mathrm{~min}$ & $30 \mathrm{~min}$ & $1 \mathrm{~h}$ & $2 \mathrm{~h}$ & $4 \mathrm{~h}$ & $24 \mathrm{~h}$ & \\
\hline & \multicolumn{10}{|c|}{ GRUPO 1} & \\
\hline P. edulis & $0,70^{2}$ & 0,0 & $0,76^{2}$ & 0,0 & $0,86^{2}$ & $0,86^{2}$ & $0,97^{2}$ & $1,01^{2}$ & $0,97^{2}$ & $0,97^{2}$ & 711,67 \\
\hline P. gibertii & 0,70 & 0,0 & 0,86 & 0,0 & 0,81 & 0,81 & 0,76 & 0,81 & 0,81 & 1,07 & 716,09 \\
\hline P. alata & 0,76 & 0,0 & 0,76 & 0,0 & 0,76 & 0,76 & 0,76 & 0,76 & 1,01 & 0,86 & 721,28 \\
\hline Sul Brasil & 0,76 & 0,0 & 0,70 & 0,0 & 0,81 & 0,81 & 0,81 & 0,81 & 0,81 & 0,97 & 711,90 \\
\hline IAC-275 & 0,70 & 0,0 & 0,70 & 0,0 & 0,76 & 0,76 & 0,81 & 0,76 & 0,81 & 0,86 & 715,59 \\
\hline Flora FB-300 & 0,70 & 0,0 & 0,70 & 0,0 & 0,91 & 0,91 & 0,97 & 0,97 & 1,01 & 0,91 & 717,05 \\
\hline $\mathrm{F}$ (tratamento) & $0,80^{\text {ns }}$ & - & $0,90^{\text {ns }}$ & - & $0,78^{\text {ns }}$ & $0,78^{\text {ns }}$ & $2,26^{\mathrm{ns}}$ & $2,49^{\text {ns }}$ & $1,86^{\text {ns }}$ & $0,91^{\mathrm{ns}}$ & $2,18^{\text {ns }}$ \\
\hline \multirow[t]{3}{*}{ C.V. $(\%)$} & 13,05 & - & 22,76 & - & 26,50 & 26,50 & 25,68 & 25,96 & 27,06 & 27,74 & 1,06 \\
\hline & \multicolumn{10}{|c|}{ GRUPO 2} & \\
\hline & $1 \mathrm{~min}$ & $3 \min$ & $5 \min$ & $10 \mathrm{~min}$ & $15 \mathrm{~min}$ & $30 \mathrm{~min}$ & $1 \mathrm{~h}$ & $2 \mathrm{~h}$ & $4 \mathrm{~h}$ & $24 \mathrm{~h}$ & \\
\hline P. edulis & $0,86 \mathrm{a}^{1}$ & $0,81^{1}$ & $0,91 \mathrm{a}^{1}$ & $1,07 \mathrm{a}^{1}$ & $0,97^{1}$ & $0,86^{1}$ & $0,86^{1}$ & $0,91^{1}$ & $0,81^{1}$ & $0,76^{1}$ & 710,39 \\
\hline P. alata & $0,71 \mathrm{~b}$ & 0,71 & $0,71 \mathrm{~b}$ & $0,71 \mathrm{~b}$ & 0,81 & 0,81 & 0,81 & 0,81 & 0,81 & 0,81 & 701,10 \\
\hline P. serrato-digitata & $0,71 \mathrm{~b}$ & 0,71 & $0,71 \mathrm{~b}$ & $0,81 \mathrm{ab}$ & 0,81 & 0,97 & 1,02 & 0,91 & 0,81 & 0,81 & 711,79 \\
\hline P. edulis f. flavicarpa & $0,71 \mathrm{~b}$ & 0,71 & $0,76 \mathrm{ab}$ & $0,97 \mathrm{ab}$ & 1,07 & 1,12 & 1,02 & 0,97 & 0,71 & 0,81 & 708,71 \\
\hline Maguary FB-100 & $0,71 \mathrm{~b}$ & 0,71 & $0,71 \mathrm{~b}$ & $0,91 \mathrm{ab}$ & 0,86 & 0,97 & 0,97 & 1,01 & 0,71 & 0,81 & 711,22 \\
\hline F (Tratamento) & $3,86^{* *}$ & $2,25^{\mathrm{ns}}$ & $4,09^{* *}$ & $3,82^{* *}$ & $2,14^{\mathrm{ns}}$ & $2,32^{\text {ns }}$ & $1,35^{\text {ns }}$ & $0,88^{\mathrm{ns}}$ & $1,13^{\mathrm{ns}}$ & $0,12^{\text {ns }}$ & $1,47^{\text {ns }}$ \\
\hline \multirow[t]{3}{*}{ C. V. $(\%)$} & 15,15 & 13,41 & 18,47 & 25,33 & 26,86 & 26,20 & 27,38 & 28,06 & 21,98 & 26,05 & 0,17 \\
\hline & \multicolumn{10}{|c|}{ GRUPO 3} & \\
\hline & $1 \mathrm{~min}$ & $3 \min$ & $5 \mathrm{mi}$. & $10 \mathrm{~min}$ & $15 \mathrm{~min}$ & $30 \mathrm{~min}$ & $1 \mathrm{~h}$ & $2 \mathrm{~h}$ & $4 \mathrm{~h}$ & $24 \mathrm{~h}$ & \\
\hline P. edulis & $0,86^{2}$ & $0,91^{2}$ & $0,91^{2}$ & $1,02^{2}$ & $0,91^{2}$ & $0,76 b^{2}$ & $0,91^{2}$ & $0,97^{2}$ & $1,12 \mathrm{ab}^{2}$ & $0,81 \mathrm{ab}^{2}$ & 704,70 \\
\hline P. alata & 0,91 & 0,86 & 0,86 & 0,91 & 0,96 & $0,86 \mathrm{ab}$ & 0,97 & 1,02 & $0,97 \mathrm{~b}$ & $0,76 \mathrm{ab}$ & 700,49 \\
\hline Sul Brasil & 0,76 & 0,86 & 0,81 & 0,91 & 0,91 & $0,91 \mathrm{ab}$ & 1,02 & 1,02 & $1,12 \mathrm{ab}$ & $0,81 \mathrm{ab}$ & 710,00 \\
\hline$P$. serrato-digitata & 0,91 & 0,91 & 1,01 & 0,97 & 0,97 & $1,17 \mathrm{a}$ & 1,17 & 1,17 & $1,22 \mathrm{a}$ & $0,76 \mathrm{ab}$ & 701,40 \\
\hline P. edulis f. flavicarpa & 0,86 & 0,86 & 0,86 & 0,91 & 0,76 & $0,91 \mathrm{ab}$ & 1,07 & 0,97 & $1,22 \mathrm{a}$ & $0,81 \mathrm{ab}$ & 700,80 \\
\hline Maguary FB-100 & 0,76 & 0,81 & 0,97 & 1,02 & 0,97 & $0,86 \mathrm{ab}$ & 1,07 & 1,12 & $1,12 \mathrm{ab}$ & $0,71 \mathrm{~b}$ & 702,30 \\
\hline$P$. foetida & 0,71 & 0,71 & 0,81 & 0,86 & 0,91 & $1,02 \mathrm{ab}$ & 0,91 & 1,02 & $1,02 \mathrm{ab}$ & $1,02 \mathrm{a}$ & 703,80 \\
\hline F (Tratamento) & $1,50^{\text {ns }}$ & $0,94^{\text {ns }}$ & $0,98^{\text {ns }}$ & $0,49^{\text {ns }}$ & $0,81^{\mathrm{ns}}$ & $3,14^{* *}$ & $1,19^{\text {ns }}$ & $0,98^{\mathrm{ns}}$ & $2,26^{* *}$ & $2,57^{*}$ & $1,42^{\text {ns }}$ \\
\hline C. V. $(\%)$ & 25,97 & 27,42 & 28,03 & 28,16 & 28,18 & 25,51 & 24,56 & 24,05 & 18,24 & 24,14 & 0,23 \\
\hline
\end{tabular}

Média transformada em $\ln (\mathrm{x}+5,0)$.

${ }^{2}$ Médias transformadas em $(x+0,5)^{1 / 2}$

Médias seguidas de mesma letra dentro de cada grupo, na coluna, não diferem significativamente, pelo teste de Tukey, a $5 \%$ de probabilidade.

\section{CONCLUSÕES}

O genótipo $P$. alata é menos atrativo e consumido por lagartas de D. juno juno recém-eclodidas e de 10 dias de idade, em testes com e sem chance de escolha. No teste sem chance de escolha, $P$. foetida também se destaca pelos baixos índices de atratividade e consumo.

\section{REFERÊNCIAS}

AGRIANUAL 2006: anuário da agricultura brasileira. São Paulo: FNP, 2006.

BIANCHI, V.; MOREIRA, G.R.P. Preferência alimentar, efeito da planta hospedeira e da densidade larval na sobrevivência e desenvolvimento de Dione juno juno (Cramer) (Lepidoptera, Nymphalidae). Revista Brasileira de Zoologia, Curitiba, v.22, n.1, p.43-50, 2005.

BOIÇA JR., A.L. Resistência de maracujazeiro (Passiflora spp.) a Dione juno juno (Cramer, 1779) (Lepidoptera, Nymphalidae) e determinação dos tipos envolvidos. 1994. 218 f. Tese (Livre-Docência) - Faculdade de Ciências Agrárias e Veterinárias, Universidade Estadual Paulista, Jaboticabal, 1994.

BOIÇA JR., A.L.; LARA, F.M.; OLIVEIRA, J.C. Efeito de genótipos de maracujazeiro (Passiflora spp.) e da densidade larval na biologia de D. juno juno (Cramer) (Lepidoptera:
Nymphalidae). Anais da Sociedade Entomológica do Brasil, Londrina, v.28, p.41-47, 1999.

ECHEVERRI, F.; CARDONA, G.; TORRES, F.; PELAEZ, C.; QUIÑONES, W.; RENTERIA, E. Ermanin: An insect deterrent flavonoid from Passiflora foetida Resin. Phytochemistry, Medellin, v.30, n.1, p.153-155. 1991.

FANCELLI, M. Insetos-pragas do maracujazeiro e controle. In: LIMA, A.A. et al. Instruções práticas para o cultivo do maracujazeiro. Cruz das Almas: Empresa Brasileira de Pesquisa Agropecuária, 1994. 49p. (Circular Técnica, 20).

FANCELLI, M. Maracujá em foco: as lagartas desfolhadoras do maracujazeiro. Cruz das Almas: Empresa Brasileira de Pesquisa Agropecuária, 1998.p.1. (Circular Técnica, 50)

LARA, F.M.; BOIÇA JR., A.L.; BARBOSA, J.C. Preferência alimentar de Dione juno juno (Cramer) por genótipos de maracujazeiro e avaliação do uso de extratos aquosos. Scientia Agrícola, Piracicaba, v.56, n.3, p.665-671. 1999.

LARA, F.M. Princípios de resistência de plantas a insetos. São Paulo: Ícone, 1991.336p.

PICANÇO, M.C.; GUEDES, R.N.C.; BATALHA, V.C.; CAMPOS, R.P. Toxicity of insecticides to Dione juno juno (Lepidoptera: Heliconidae) and selectivity to two of its predaceous bugs. Tropical Science, London, v.36, n.1, p.51-53, 1996.

SANTOS, Z.F.A.F.; COSTA, J.M. Pragas da cultura do maracujá no Estado da Bahia. Salvador: EMATER/EPABA, 1983. (Circular Técnica, 4). 